\title{
Pricing in C2C Sharing Platforms
}

\author{
Peter Angerer ${ }^{\dagger}$ \\ Daniel Provin ${ }^{\dagger}$ \\ Steffen Zimmermann ${ }^{\dagger}$ \\ Barrie R. Nault ${ }^{\dagger}$ \\ †School of Management \\ University of Innsbruck \\ \{firstname\}.\{lastname\}@uibk.ac.at \\ ${ }^{\dagger}$ Haskayne School of Business \\ University of Calgary \\ nault@ucalgary.ca
}

July 23, 2017

We thank the participants of the Conference on Information Systems and Technology (CIST), 2015 in Philadelphia, PA for helpful feedback. We also thank Jeanette Burman for helpful comments and editing. This work is supported by the Natural Science and Engineering Research Council of Canada, the Social Science and Humanities Research Council of Canada, and the IRC at the Haskayne School of Business at the University of Calgary.

Copyright (c) 2017 by Peter Angerer, Daniel Provin, Steffen Zimmermann and Barrie R. Nault. All rights reserved. 


\title{
Pricing in C2C Sharing Platforms
}

\begin{abstract}
Sharing platforms such as Zilok.com enable the sharing of durable goods among consumers, and seek to maximize profits by charging transaction-based platform fees. We develop a model where consumers that are heterogeneous in their need to use a durable good decide whether to purchase and share (i.e., be a lender) or borrow (i.e., be a borrower), and a monopoly sharing platform decides on the platform fees. We find first that consumers with a greater need to use a durable good purchase and share, and that consumers with a lesser need borrow. Second, sharing platforms maximize profits only if the supply of a durable good matches demand - that is, the market must clear for platform fees to be profit maximizing. Third, the market-clearing condition requires that lender and borrower fees are classic strategic complements. Fourth, to maintain the market-clearing condition, sharing platforms have to increase their lender fee or decrease their borrower fee in response to increases in the sharing price, increases in usage capacity, and decreases in the purchase price of a durable good, and vice versa. These findings indicate that commonly applied one-sided pricing models in sharing platforms can be improved.
\end{abstract}

Keywords: Sharing Economy, Sharing Platforms, Durable Good, Consumer Behavior, Platform Pricing Behavior. 


\section{Introduction}

Consumers own a substantial amount of underutilized durable goods. For instance in the U.S. consumers own approximately 50 million power drills, which are on average used only six to thirteen minutes until they are replaced (Botsman \& Rogers, 2010). Granting other consumers access to the unused capacity of durable goods represents the underlying idea in the emerging sharing economy. The sharing economy is expected to grow to $\$ 335$ billion by 2025 ( $\mathrm{PwC}, 2015)$. This rise is mainly driven by consumers that increasingly favor paying for temporary access to durable goods instead of buying and owning them (Dervojeda et al., 2013) and by consumer-to-consumer (C2C) sharing platforms such as Zilok.com which enable the distribution of excess capacity of underutilized durable goods by giving consumers the opportunity to share them.

The $\mathrm{C} 2 \mathrm{C}$ sharing market is characterized by four classes of participants (cf., Dervojeda et al., 2013). First are producers or retailers that sell (durable) goods to consumers and charge a purchase price. Next, lenders are consumers that purchase goods and grant other consumers temporary access to this good by charging a sharing price. On the other hand, borrowers are consumers that do not purchase, but aim to get temporary access to a durable good by paying a sharing price. Finally, sharing platforms are accessibility-based systems that provide mediating services facilitating sharing transactions between lenders and borrowers and can charge platform fees to both groups. Figure 1 illustrates the participants and their interplay in the $\mathrm{C} 2 \mathrm{C}$ sharing market.

In the context of a $\mathrm{C} 2 \mathrm{C}$ sharing market, we consider commercial sharing of durable goods such as a power drill which is enabled by a $\mathrm{C} 2 \mathrm{C}$ sharing platform such as Zilok.com. In our model lenders and borrowers maximize utility, the sharing platform maximizes profit, and we take the purchase price of the good from the producer or retailer as given. To make our analysis concrete, we use the example of sharing a power drill through a sharing platform such as Zilok.com as a running 


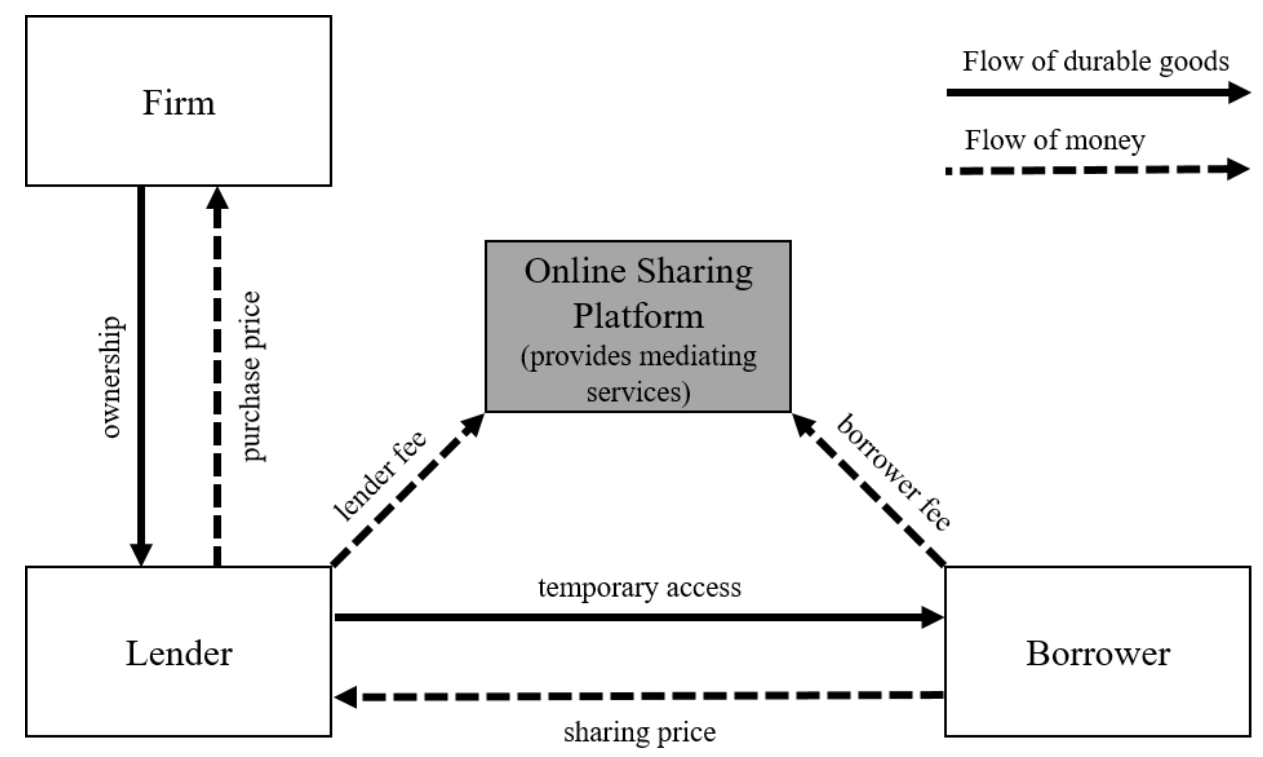

Figure 1: C2C Sharing Market

example throughout.

The objective of a $\mathrm{C} 2 \mathrm{C}$ sharing platform is to enable sharing transactions and maximize profits by charging a transaction-based platform fee to lenders and/or a transaction-based platform fee to borrowers. It is not sufficient to simply set optimal platform fees once. Rather, sharing platforms have to be aware of changes in external factors (i.e., factors a sharing platform is not accountable for). Such external factors include the purchase price which is set by producers or retailers, the sharing price which is set by the lender, and the usage capacity (hereafter, capacity) of a durable good which can be influenced by the lender through repairing or replacing worn parts representing investments in capacity. Changes in these external factors may influence supply and demand, and require consequent responses in the platform fees.

Our analysis and our running example only refers to the $\mathrm{C} 2 \mathrm{C}$ sharing part of Zilok.com. There are other forms of sharing that our analysis does not cover. We do not consider altruistic sharing, commodity exchange, and gift giving among family members and friends (Belk, 2010). Our focus 
is separate from sharing of perishable goods such as food (e.g., provided by Olioex.com), intangible goods such as services (e.g., transportation provided by Uber.com), and digital goods such as music (e.g., provided by Spotify.com). In addition, our focus is separate from luxury goods because consumers are typically not willing to share expensive and valuable goods. We also do not consider business-to-consumer (B2C) sharing enabled by B2C sharing platforms such as car2go.com.

Accordingly, we address the following research question: What is the optimal pricing behavior of C2C sharing platforms to maximize profits in response to changes in external factors?

To answer our research question, we develop a two-stage model. In the first stage, a monopoly sharing platform maximizes profits by setting prices in a two-sided market structure (cf., Armstrong, 2006; Rochet \& Tirole, 2006; Rysman, 2009). In the second stage, we analyze the behavior of consumers that differ in their need to use a durable good whereby consumers decide whether to purchase and share (i.e., be a lender) or borrow (i.e., be a borrower) to maximize their net utility (cf., Becker, 1976). In using this two-stage formulation, we are in line with Knote and Blohm (2016) that identified the understanding of multi-sided principles and pricing models of sharing platforms as the most important knowledge gaps in understanding the sharing economy. An innovation embedded in our formulation is that consumers decide which side of the market they are on as part of our model. This is a departure from most of the two-sided market literature where the participants on the two sides are pre-determined.

Our analysis yields a series of results. We find first that consumers with a greater need to use a durable good purchase and share, and consumers with a lesser need to use borrow that good. Second, sharing platforms maximize profits only if the supply of a durable good matches demand - that is, the market must clear for platform fees to be profit maximizing. Third, the marketclearing condition requires that lender and borrower fees are classic strategic complements. Fourth, 
to maintain the market-clearing condition, sharing platforms have to increase their lender fee or decrease their borrower fee in response to increases in the sharing price, increases in capacity, and decreases in the purchase price of a durable good, and vice versa. These findings indicate that commonly-applied one-sided pricing models of sharing platforms can be improved.

We structure our work as follows: We begin by discussing the related literature to position our research question. Next, we define our notation and explain our assumptions. Subsequently, we solve our two-stage model in reverse order by analyzing consumer behavior and then analyzing optimal pricing behavior by a monopoly sharing platform. Finally, we conclude by presenting managerial implications and discussing implications for future research.

\section{Related Literature}

We structure this section according to our analysis sequence by first discussing articles that investigate consumer behavior in the sharing economy followed by a discussion of articles that analyze sharing platform behavior. Of course, there are articles that address other aspects of the sharing economy such as the consequences on traditional firms (e.g., Cusumano, 2015; Malhotra \& Van Alstyne, 2014; Zervas, Proserpio, \& Byers, 2014). We do not cover this literature as it is unrelated to our model and contribution.

Consumer Behavior: Belk (2007) argues that sharing is able to foster communities, save resources, and create synergies for consumers. Furthermore, in describing cost savings as the main motive, the article draws a comparison to companies that increasingly outsource operations in order to lower costs, and argues that for similar reasons consumers will increasingly share their owned goods to reduce their total costs of ownership. Botsman and Rogers (2010) also argue that beside the advantage for consumers of saving money, sharing lowers environmental damage and encourages 
the development of better products. Phipps et al. (2013) introduce a conceptual framework based on social cognitive theory, and argue that besides saving money consumers receive further benefits from the sharing economy such as community building of like-minded people and the emergence of sustainable spaces to meet. Sundararajan (2016) depicts a broad and visionary picture of the sharing economy as "crowd-based capitalism", making the point that sharing will lead to higher utilization of product capacity and that the complex microstructure of the sharing economy requires a set of models. Moehlmann (2015) studies data from Airbnb.com and finds that the likelihood of choosing a sharing option is predominantly determined by users' self-benefit and cost savings, whereas environmental considerations are negligible. Having in mind the different motives that drive consumers to participate in the sharing economy we focus on cost savings as they are the most widely agreed upon reason for participating in the $\mathrm{C} 2 \mathrm{C}$ sharing market.

Matzner, Chasin, and Todenhoefer (2015) present an empirical study based on the theory of planned behavior, where they represent lenders and borrowers as part of the same consumer group and acknowledge that consumers can independently decide how they participate in the $\mathrm{C} 2 \mathrm{C}$ sharing market. We follow this view of consumers in our model whereby consumers choose whether to lend or borrow endogenously. Chen (2009) empirically studies the need and perceived values of art consumers and finds that art collectors and exhibit visitors differ in their need to consume art leading to different consumer groups, namely ownership for the art collector and access for the exhibit visitor. Accordingly, we consider consumers that differ in their need to use a durable good, and our model confirms the finding in Chen (2009) that consumers with a greater need aim to own rather than simply access a durable good.

Lamberton and Rose (2012) draw from three different studies and empirically find that the rational consumer utility model is applicable to commercial sharing. Thus, we use rational consumer 
behavior to inform our model. Fraiberger and Sundararajan (2015) build a theoretical model for peer-to-peer sharing of durable goods where consumers are also allowed to trade their durable goods through secondary markets. They calibrate their model with data of the US automobile industry and transaction data of the car sharing platform Getaround. The results show a decrease in ownership but increase in utilization and consumer welfare due to the availability of a sharing market: below median income consumers have a significantly higher improvement and also provide a majority of sharing supply. Mueller (2014) theorizes the behavior of consumers participating in the $\mathrm{C} 2 \mathrm{C}$ sharing market and considers consumers which are heterogeneous in the value gained from using a durable good. We adopt this model setup as our starting point, and analyze the implications of consumer behavior on platform pricing behavior.

Platform Behavior: Einav et al. (2016) find that successful platforms need to set the sharing price to balance demand and supply. They argue that auctions might be suitable because they allow prices to respond to market conditions, but also that consumers tend to be less interested in auctions now than fifteen years ago. As a result, they call for a simpler pricing mechanism that makes use of available information that can effectively substitute for auctions. Moreover, on most sharing platforms, the sharing price is set by the lender and not by the platform. In contrast to Einav et al. (2016), we analyze and find pricing mechanisms for platform fees instead of the sharing price to balance demand and supply for maximizing profits. Weber (2014) analyzes how a sharing platform is able to eliminate moral hazard between lenders and borrowers. In the collaborative housing market, where heterogeneous borrowers and vertically differentiated lenders (in terms of housing quality) can use Airbnb.com as a sharing platform to increase the matching probability, the sharing platform offers a form of insurance that requires borrowers to make a deposit and gives lenders the ability to file claims if damage occurs. Weber (2014) assumes that the sharing platform, in turn, charges symmetric platform fees to lenders and borrowers for the mediating services, and 
finds that if all participants are risk neutral, then the sharing platform is able to cover all lenders' claims while providing incentives to borrowers to behave as lenders would if using their own space.

The literature discussed above is summarized in Table 1 according to its content and method.

\begin{tabular}{|c|c|c|}
\hline Content & Consumer Behavior & Platform Behavior \\
\hline $\begin{array}{l}\text { Descriptive/ } \\
\text { Conceptual }\end{array}$ & $\begin{array}{l}\text { Belk (2007) } \\
\text { Botsman and Rogers (2010) } \\
\text { Phipps et al. (2013) } \\
\text { Sundararajan (2016) }\end{array}$ & Einav et al. (2016) \\
\hline Empirical & $\begin{array}{l}\text { Moehlmann (2015) } \\
\text { Matzner et al. (2015) } \\
\text { Chen (2009) } \\
\text { Lamberton and Rose (2012) }\end{array}$ & \\
\hline Theoretical & $\begin{array}{l}\text { Fraiberger and Sundararajan (2015) } \\
\text { Mueller (2014) }\end{array}$ & Weber (2014) \\
\hline
\end{tabular}

Table 1: Related Literature

In our literature review on the sharing economy, we found that Consumer Behavior is investigated more extensively than Platform Behavior - only Weber (2014) theoretically analyzes Platform Behavior as we do in the context of a $\mathrm{C} 2 \mathrm{C}$ sharing market. In contrast to that work, our formulation supposes potentially asymmetric platform fees, which allows us to operationalize the concept of subsidizing one side over the other that is common in the two-sided platforms literature (cf., Caillaud \& Jullien, 2003; Eisenmann, Parker, \& Van Alstyne, 2006; Rysman, 2009). Moreover, we focus on the directional changes in platform pricing as a response to changing external factors such as changes in the durable good's purchase price and capacity. Our model further applies to C2C sharing platforms for durable goods in general and abstracts from a specific platform or product. We further abstract from specific utility functions, using a reduced-form utility function for lenders and borrowers, allowing us to develop more general results. In doing so, we show how sharing platforms can dynamically maximize profits by adapting their platform fees based on changes in external factors. 
The structure of our model is related to that of Brock and Evans (1985) where individual entrepreneurs make production decisions and a policy-maker decides on a tax schedule to maximize welfare. Our model is also related to Nault (1996) and Levi and Nault (2004) where firms decide whether to convert to a new technology and a policy-maker offers different tax regimes that impact firms' choices of whether to convert. The essential differences in our model are that we have consumers that decide on whether to purchase and share, or borrow a durable good, rather than firms that decide between technologies. Moreover, we consider a sharing platform that decides on platform fees to maximize profits instead of a policy maker that decides on tax schedules. Finally, and most importantly, we consider a two-sided market, where differing platform fees can be charged to lenders and to borrowers.

Two-sided markets are usually characterized by strong network externalities, which in a winnertake-all setting often result in a monopoly platform (cf., Eisenmann et al., 2006; Rysman, 2009). Accordingly, we take the sharing platform to be a monopoly in our model, and abstract from the conditions that may have led to the platform being a monopoly. A monopoly setting is reasonable because two-sided platforms do not face diminishing returns when growing beyond a certain point as lenders usually benefit from a large number of borrowers and vice versa, leading to winner-takeall market consolidations where a single platform serves almost the whole market. Such market consolidations have taken place in other two-sided markets such as online social networking with Facebook, online auctions with eBay, and web search with Google being the dominant platforms (Eisenmann et al., 2006).

Nevertheless, the challenge of two-sided platforms to be successful is to get both sides of the market (in our case borrowers and lenders) on board (Rochet \& Tirole, 2006). This can be achieved by a platform pricing behavior that accounts for externalities on both sides. Pricing in two-sided 
markets includes the opportunity of (relative) subsidizing one side over the other side (cf., Armstrong, 2006; Caillaud \& Jullien, 2003; Eisenmann et al., 2006; Rysman, 2009). Such pricing strategies can compensate different price elasticities (Rysman, 2009) and different numbers of participants in both sides (Eisenmann et al., 2006), consequently impacting overall transaction volume and platform profits (Lee \& Wu 2009). In our model, we allow for asymmetric pricing as well as different price elasticities for supply and demand of a durable good.

\section{Notation and Assumptions}

Our assumptions pertain to a number of different factors relating to consumer heterogeneity, consumer utility, and platform fees.

We consider consumers that participate in the $\mathrm{C} 2 \mathrm{C}$ sharing market. For these consumers, it is economically worthwhile to either purchase and share, or borrow a durable good. We exclude consumers that are neither willing to purchase nor to borrow a durable good or that prefer outside options such as face-to-face sharing between friends and family members or other alternatives. Our first assumption is about those consumers that participate in the $\mathrm{C} 2 \mathrm{C}$ sharing market.

Assumption 1 (Consumer Heterogeneity). Consumers differ in their need to use a durable good.

Consistent with Alba et al. (1997), we assume consumers are heterogeneous in their need to use a durable good and denote consumers as $\theta$, which is normalized in the interval $[0,1]$. Thus, $f(\theta)>0 \forall \theta \in[0,1], F(0)=0$ and $F(1)=1 . \theta$ represents an increasing need to use a durable good in a way that consumers with $\theta=0$ are those that have the lowest need, while consumers with $\theta=1$ are those that have the greatest need. $\theta$ is taken to be uniformly distributed over its range. This incurs little loss of generality as $\theta$ can be scaled as needed.

In our running example of sharing a power drill, a consumer with a greater need to use a power 
drill (high $\theta$ ) could be an individual that enjoys artisanal work at home (hereafter, handy-person). A consumer with a lesser need to use a power drill (low $\theta$ ) could be an individual who dislikes doing artisanal work at home (hereafter, non-handy-person).

The amount of time consumers aim to use a durable good is denoted by $x \in[0, \bar{x}]$ with the subscript L for the own usage time of lenders and with the subscript $\mathrm{B}$ for the demanded usage time of borrowers. The amount of time a lender aims to share a durable good is called supplied usage time and denoted by $y \in[0, \bar{x}]$. As borrowers typically maximize the usage of a durable good in the available time, the amount of time a lender actually shares a durable good (i.e., shared usage time) is equal to the actual usage time of the durable good by borrowers. Otherwise, borrowers would just pay for the availability of the durable good without using it. $x$ and $y$ are bounded from below as using a durable good for a negative time is infeasible and bounded from above by the durable good?s usage capacity $\bar{x}$. For example, a power drill typically fails after a specific amount of operating hours. The durable good considered for sharing in our model is homogeneous (not vertically differentiated) and represents the best economic choice with a minimum price/performance ratio $\left(p_{P} / \bar{x}\right)$ out of different products of a product type such as power drills. This means that a consumer decides whether to purchase and share or borrow the power drill having the best ratio between purchase price and capacity.

The monetary utility of a consumer depends on the need to use a durable good, $\theta$, and the usage time $x$ (i.e., own usage time, $x_{L}$, for lenders or demanded usage time, $x_{B}$, for borrowers). We denote this utility by a reduced-form utility function $U(\theta, x)$, which is bounded from below $U(\theta, 0)=0$. We take a consumer's utility as increasing in the need to use a durable good, and increasing and concave in the usage time to its capacity $\bar{x}$. The latter represents the standard assumption of decreasing marginal utility. 
Assumption 2 (Consumer Utility).

$$
\frac{\partial U(\theta, x)}{\partial \theta}>0, \quad \frac{\partial U(\theta, x)}{\partial x}>0 \quad \text { and } \quad \frac{\partial^{2} U(\theta, x)}{\partial x^{2}}<0 .
$$

For example, the utility gained from using a power drill is higher for a handy-person compared to a non-handy-person. Moreover, the utility from using a power drill increases in the usage time while the marginal utility from using the power drill decreases because a consumer typically drills the more important holes before the less important ones and the drill wears out through usage.

Given the nature of the consumer's utility function, there is a relationship between the usage time and the consumer's need to use a durable good. This cross effect is fundamental to the results in that a consumer's marginal utility is increasing in the need to use a durable good.

\section{Assumption 3 (Cross Effect).}

$$
\frac{\partial^{2} U(\theta, x)}{\partial x \partial \theta}>0
$$

This means in our example that a handy-person experiences a higher marginal utility from using a power drill compared to a non-handy-person.

Consumers in the $\mathrm{C} 2 \mathrm{C}$ sharing market can either purchase and share, or borrow a durable good. Lenders purchase a durable good for a purchase price, $p_{P} \in R^{+}$, and charge borrowers a sharing price per unit of shared usage time, $p_{S} \in R^{+}$.

The mediating services to connect lenders and borrowers are provided by a monopoly sharing platform (e.g., Eisenmann et al., 2006; Rysman, 2009). The monopoly platform is limited to intermediation: it does not compete with traditional firms outside the domain of sharing such as is the case with Airbnb.com that competes with the hotel industry. As stated earlier, we consider consumers for whom participating in the $\mathrm{C} 2 \mathrm{C}$ sharing market is economically worthwhile and for these consumers there is no alternative $\mathrm{C} 2 \mathrm{C}$ sharing platform over which to share a durable good. 
Assumption 4 (Platform Fees). The monopoly sharing platform sets non-negative transactionbased platform fees to lenders and borrowers.

To maximize profits, the sharing platform sets a transaction-based lender fee, $s_{L} \in\left[0, p_{S}\right]$, and a transaction-based borrower fee, $s_{B} \in\left[0, p_{P}\right]$ (cf., Armstrong, 2006). The lender fee is limited by $p_{S}$ because with a lender fee greater than the sharing price, no lender would have an incentive to share a durable good. The borrower fee is limited by $p_{P}$ because with a borrower fee greater than the purchase price, all borrowers would purchase the durable good. These weakly positive transactionbased fees allow for subsidizing one group over the other to compensate different numbers of lenders and borrowers and different price elasticities (cf., Caillaud \& Jullien, 2003; Eisenmann et al., 2006; Rysman, 2009). We do not allow for negative fees (i.e., subsidizing lenders and/or borrowers for making sharing transactions via the sharing platform) as the sharing platform has to cover fixed costs $C \in R^{+}$for providing the mediating services and we do not observe any sharing platform operating in the sharing market that is currently charging negative fees. This indicates that sharing platforms have to generate revenue from charging positive platform fees, $s_{L}+s_{B} \in R^{+}$, to be profitable.

In practice sharing platforms charge a percent-of-value lender fee and/or a percent-of-value borrower fee, which represent a percentage rate of the total sharing price $\left(p_{S} * \min \left\{y, x_{B}\right\}\right.$ in our model). Hence, in such implemented pricing models, platform fees are increasing in the sharing price and in the shared usage time. In contrast, we intentionally use unit transaction fees, which only increase in the shared usage time, as our basic pricing model. We do this in order to examine whether commonly applied percent-of-value platform fees are profit maximizing or whether they can be replaced by a better pricing model. 


\section{Model Set-Up}

We set up our $\mathrm{C} 2 \mathrm{C}$ sharing market model as a two-stage model. In the first stage, the monopoly sharing platform sets transaction-based platform fees to borrowers and lenders. In the second stage, consumers maximize their net utility by deciding to be a lender or a borrower based on their individual need and the resulting expected own or demanded usage time of a durable good. In our two-stage model, we work backwards and examine consumer behavior first and platform pricing second.

\subsection{Consumer Behavior}

Borrowers: For a borrower, the net utility $\phi_{B}$ includes the sharing price paid to the lender and the borrower fee paid to the sharing platform:

$$
\phi_{B}=U\left(\theta, x_{B}\right)-p_{S} * x_{B}-s_{B} * x_{B}>0,
$$

where we subscript the borrower-specific variables with $B$. We take $U\left(\theta, x_{B}>0\right)$ to be sufficiently large so that (1) is positive for all borrowers. Otherwise, borrowers would not borrow and consequently not participate in the $\mathrm{C} 2 \mathrm{C}$ sharing market. For borrowers the first-order condition by choice of demanded usage time is

$$
\frac{\partial \phi_{B}}{\partial x_{B}}=\frac{\partial U\left(\theta, x_{B}\right)}{\partial x_{B}}-p_{S}-s_{B}=0=\omega\left(\theta, x_{B}, p_{S}, s_{B}\right)
$$

where $\omega\left(\theta, x_{B}, p_{S}, s_{B}\right)$ implicitly defines the optimal value function $x_{B}\left(\theta, p_{S}, s_{B}\right)$. Lemma 1 describes the behavior of $x_{B}\left(\theta, p_{S}, s_{B}\right)$.

Lemma 1. For borrowers, the demanded usage time is increasing in their need to use a durable good and is decreasing in the sharing price and the borrower fee. 
Proof: From Assumption 3, we have

$$
\frac{\partial \omega\left(\theta, x_{B}, p_{S}, s_{B}\right)}{\partial \theta}=\frac{\partial^{2} U\left(\theta, x_{B}\right)}{\partial x_{B} \partial \theta}>0 .
$$

The sign of the second-order condition follows directly from Assumption 2 and is

$$
\frac{\partial \omega\left(\theta, x_{B}, p_{S}, s_{B}\right)}{\partial x_{B}}=\frac{\partial^{2} U\left(\theta, x_{B}\right)}{\partial x_{B}^{2}}<0
$$

Directly from the implicit function rule, we have

$$
\begin{gathered}
\frac{\partial x_{B}}{\partial \theta}=-\frac{\partial \omega\left(\theta, x_{B}, p_{S}, s_{B}\right) / \partial \theta}{\partial \omega\left(\theta, x_{B}, p_{S}, s_{B}\right) / \partial x_{B}}=-\frac{\partial^{2} U\left(\theta, x_{B}\right) / \partial x_{B} \partial \theta}{\partial^{2} U\left(\theta, x_{B}\right) / \partial x_{B}^{2}}>0 \\
\frac{\partial x_{B}}{\partial p_{S}}=-\frac{\partial \omega\left(\theta, x_{B}, p_{S}, s_{B}\right) / \partial p_{S}}{\partial \omega\left(\theta, x_{B}, p_{S}, s_{B}\right) / \partial x_{B}}=-\frac{-1}{\partial^{2} U\left(\theta, x_{B}\right) / \partial x_{B}^{2}}<0 \\
\frac{\partial x_{B}}{\partial s_{B}}=-\frac{\partial \omega\left(\theta, x_{B}, p_{S}, s_{B}\right) / \partial s_{B}}{\partial \omega\left(\theta, x_{B}, p_{S}, s_{B}\right) / \partial x_{B}}=-\frac{-1}{\partial^{2} U\left(\theta, x_{B}\right) / \partial x_{B}^{2}}<0 .
\end{gathered}
$$

Q.E.D.

In our running example Lemma 1 implies that a handy-person (high $\theta$ ) that borrows a power drill aims to use the drill for a longer time compared to a borrower that dislikes artisanal work (low $\theta$ ). Moreover, borrowers increase their demanded usage time with a decreasing sharing price and a decreasing borrower fee they have to pay when borrowing a power drill.

The effects on $x_{B}$ in the proof of Lemma 1 represent the borrowers' individual elasticities of demand for sharing a durable good. We refer to these elasticities later.

Lenders: For a lender, the net utility $\phi_{L}$ includes the sharing price received from the borrower, the lender fee paid to the sharing platform, and the purchase price paid to own the durable good:

$$
\begin{gathered}
\phi_{L}=U\left(\theta, x_{L}\right)+p_{S} * y-s_{L} * y-p_{P}>0, \\
\text { s.t. } \quad x_{L}+y \leq \bar{x},
\end{gathered}
$$


where we subscript the lender-specific variables with $L$. We take $U\left(\theta, x_{L}>0\right)$ to be sufficiently large so that, together with $p_{S} * y,(3)$ is positive for all lenders. Otherwise, lenders would not purchase and share a durable good, and consequently would not participate in the $\mathrm{C} 2 \mathrm{C}$ sharing market. In order to maximize the net utility subject to the inequality constraint by choice of the two independent variables $x_{L}$ and $y$, we apply the Karush-Kuhn-Tucker (KKT) theorem (cf., Boyd \& Vandenberghe, 2004). The Lagrange function and its first-order conditions are

$$
\begin{gathered}
L=U\left(\theta, x_{L}\right)+p_{S} * y-s_{L} * y-p_{P}-\lambda_{1}\left[x_{L}+y-\bar{x}\right] \\
\frac{\partial L}{\partial x_{L}}=\frac{\partial U\left(\theta, x_{L}\right)}{\partial x_{L}}-\lambda_{1} \\
\frac{\partial L}{\partial y}=p_{S}-s_{L}-\lambda_{1}
\end{gathered}
$$

and we have the associated KKT conditions

$$
\text { (i) } \frac{\partial L}{\partial x_{L}}=0, \quad \text { (ii) } \frac{\partial L}{\partial y}=0, \quad \text { (iii) } \quad x_{L}+y \leq \bar{x} ; \lambda_{1} \geq 0 ; \lambda_{1}\left[x_{L}+y-\bar{x}\right]=0 .
$$

Lemma 2 describes the extent by which the capacity of a durable good is exploited by lenders.

Lemma 2. Lenders fully exploit the usage capacity of a durable good to maximize their net utility.

Proof: To find a solution we consider whether the constraint in (3) is binding. Suppose $x_{L}+y<\bar{x}$. From KKT condition (iii) it follows that $\lambda_{1}=0$ and from Assumption 2 it follows that $\partial L / \partial x_{L}>0$. Consequently, KKT condition (i) is violated. Now suppose $x_{L}+y=\bar{x}$. From KKT condition (iii) it follows that $\lambda_{1}>0$. Consequently, KKT condition (i) and (ii) can be fulfilled and this case represents a valid solution. Q.E.D.

In our running example Lemma 2 means that lenders of a power drill maximize their net utility if they either use or share their power drill to its capacity (or until the power drill breaks).

Setting (4) and (5) to zero, rearranging (5) and inserting into (4) we have

$$
\frac{\partial U\left(\theta, x_{L}\right)}{\partial x_{L}}-\left[p_{S}-s_{L}\right]=0=\psi\left(\theta, x_{L}, p_{S}, s_{L}\right),
$$


where $\psi\left(\theta, x_{L}, p_{S}, s_{L}\right)$ implicitly defines the optimal value function $x_{L}\left(\theta, p_{S}, s_{L}\right)$. Lemma 3 describes the behavior of $x_{L}\left(\theta, p_{S}, s_{L}\right)$.

Lemma 3. For lenders, the own usage time is increasing in their need to use a durable good, decreasing in the sharing price, and increasing in the lender fee.

Proof: From Assumption 2 we have

$$
\frac{\partial \psi\left(\theta, x_{L}, p_{S}, s_{L}\right)}{\partial x_{L}}=\frac{\partial^{2} U\left(\theta, x_{L}\right)}{\partial x_{L}^{2}}<0
$$

From Assumption 3 we have

$$
\frac{\partial \psi\left(\theta, x_{L}, p_{S}, s_{L}\right)}{\partial \theta}=\frac{\partial^{2} U\left(\theta, x_{L}\right)}{\partial x_{L} \partial \theta}>0
$$

Directly from the implicit function rule, we have

$$
\begin{aligned}
\frac{\partial x_{L}}{\partial \theta} & =-\frac{\partial \psi\left(\theta, x_{L}, p_{S}, s_{L}\right) / \partial \theta}{\partial \psi\left(\theta, x_{L}, p_{S}, s_{L}\right) / \partial x_{L}}=-\frac{\partial^{2} U\left(\theta, x_{L}\right) / \partial x_{L} \partial \theta}{\partial^{2} U\left(\theta, x_{L}\right) / \partial x_{L}^{2}}>0, \\
\frac{\partial x_{L}}{\partial p_{S}} & =-\frac{\partial \psi\left(\theta, x_{L}, p_{S}, s_{L}\right) / \partial p_{S}}{\partial \psi\left(\theta, x_{L}, p_{S}, s_{L}\right) / \partial x_{L}}=-\frac{-1}{\partial^{2} U\left(\theta, x_{L}\right) / \partial x_{L}^{2}}<0, \\
\frac{\partial x_{L}}{\partial s_{L}} & =-\frac{\partial \psi\left(\theta, x_{L}, p_{S}, s_{L}\right) / \partial s_{L}}{\partial \psi\left(\theta, x_{L}, p_{S}, s_{L}\right) / \partial x_{L}}=-\frac{1}{\partial^{2} U\left(\theta, x_{L}\right) / \partial x_{L}^{2}}>0 .
\end{aligned}
$$

Q.E.D.

In our running example Lemma 3 implies that a handy-person (high $\theta$ ) that purchases and shares its power drill, uses the drill for a longer time compared to a non-handy-person (low $\theta$ ). Moreover, lenders increase their own usage time of the power drill with a lower sharing price they receive from the borrowers and with a greater lender fee.

In order to determine the optimal supplied usage time, we use Lemma 2 and (6) to get

$$
\bar{x}=x_{L}\left(\theta, p_{S}, s_{L}\right)+y \Rightarrow \bar{x}-\frac{\partial U\left(\theta, x_{L}\right)}{\partial x_{L}}+\left[p_{S}-s_{L}\right]-y=0=\delta\left(\theta, \bar{x}, y, p_{S}, s_{L}\right)
$$

where $\delta\left(\theta, \bar{x}, y, p_{S}, s_{L}\right)$ implicitly defines the optimal value function $y\left(\theta, \bar{x}, p_{S}, s_{L}\right)$. Lemma 4 describes the behavior of $y\left(\theta, \bar{x}, p_{S}, s_{L}\right)$. 
Lemma 4. For lenders, the supplied usage time is decreasing in their need to use a durable good, is decreasing in the lender fee, is increasing in the sharing price and is increasing in capacity.

Proof: From Assumption 3 we have

$$
\frac{\partial \delta\left(\theta, \bar{x}, y, p_{S}, s_{L}\right)}{\partial \theta}=-\frac{\partial^{2} U\left(\theta, x_{L}\right)}{\partial x_{L} \partial \theta}<0
$$

Directly from the implicit function rule, we have

$$
\begin{gathered}
\frac{\partial y}{\partial \theta}=-\frac{\partial \delta\left(\theta, \bar{x}, y, p_{S}, s_{L}\right) / \partial \theta}{\partial \delta\left(\theta, \bar{x}, y, p_{S}, s_{L}\right) / \partial y}=-\frac{-\partial^{2} U\left(\theta, x_{L}\right) / \partial x_{L} \partial \theta}{-1}<0, \\
\frac{\partial y}{\partial \bar{x}}=-\frac{\partial \delta\left(\theta, \bar{x}, y, p_{S}, s_{L}\right) / \partial \bar{x}}{\partial \delta\left(\theta, \bar{x}, y, p_{S}, s_{L}\right) / \partial y}=-\frac{1}{-1}>0 \\
\frac{\partial y}{\partial p_{S}}=-\frac{\partial \delta\left(\theta, \bar{x}, y, p_{S}, s_{L}\right) / \partial p_{S}}{\partial \delta\left(\theta, \bar{x}, y, p_{S}, s_{L}\right) / \partial y}=-\frac{1}{-1}>0 \\
\frac{\partial y}{\partial s_{L}}=-\frac{\partial \delta\left(\theta, \bar{x}, y, p_{S}, s_{L}\right) / \partial s_{L}}{\partial \delta\left(\theta, \bar{x}, y, p_{S}, s_{L}\right) / \partial y}=-\frac{-1}{-1}<0 .
\end{gathered}
$$

Q.E.D.

In our running example, Lemma 4 implies that a non-handy-person (low $\theta$ ) aims to share its own power drill for a longer time compared to a handy-person (high $\theta$ ). Moreover, lenders increase their supplied usage time with higher power drill capacity, with a higher sharing price they receive from borrowers, and with a lower lender fee paid to the sharing platform.

The effects on $y$ in the proof of Lemma 4 represent the lenders' individual elasticities of supply for sharing a durable good. We refer to these elasticities later.

Indifferent consumer: Consumers maximize their net utility by deciding whether to purchase and share or borrow a durable good. That is

$$
\begin{aligned}
\max & \left\{U\left(\theta, x_{L}\left(\theta, p_{S}, s_{L}\right)\right)+p_{S} * y\left(\theta, \bar{x}, p_{S}, s_{L}\right)-s_{L} * y\left(\theta, \bar{x}, p_{S}, s_{L}\right)-p_{P}\right. \\
& \left.U\left(\theta, x_{B}\left(\theta, p_{S}, s_{B}\right)\right)-p_{S} * x_{B}\left(\theta, p_{S}, s_{B}\right)-s_{B} * x_{B}\left(\theta, p_{S}, s_{B}\right)\right\}
\end{aligned}
$$


We use Lemma 2 to substitute $y\left(\tilde{\theta}, \bar{x}, p_{S}, s_{L}\right)$ with $\bar{x}-x_{L}\left(\tilde{\theta}, p_{S}, s_{L}\right)$ and identify the consumer that is indifferent between purchasing and sharing, and borrowing, $\tilde{\theta}$, by

$$
\begin{aligned}
& U\left(\tilde{\theta}, x_{L}\left(\tilde{\theta}, p_{S}, s_{L}\right)\right)+p_{S} *\left(\bar{x}-x_{L}\left(\tilde{\theta}, p_{S}, s_{L}\right)\right)-s_{L} *\left(\bar{x}-x_{L}\left(\tilde{\theta}, p_{S}, s_{L}\right)\right)-p_{P} \\
& -U\left(\tilde{\theta}, x_{B}\left(\tilde{\theta}, p_{S}, s_{B}\right)\right)+p_{S} * x_{B}\left(\tilde{\theta}, p_{S}, s_{B}\right)+s_{B} * x_{B}\left(\tilde{\theta}, p_{S}, s_{B}\right)=0 \\
& =\Lambda\left(\tilde{\theta}, p_{S}, s_{L}, \bar{x}, p_{P}, s_{B}\right),
\end{aligned}
$$

where $\Lambda\left(\tilde{\theta}, p_{S}, s_{L}, \bar{x}, p_{P}, s_{B}\right)$ implicitly defines the indifferent consumer $\tilde{\theta}\left(p_{S}, s_{L}, \bar{x}, p_{P}, s_{B}\right)$. We use $(\cdot)$ for $\left(p_{S}, s_{L}, \bar{x}, p_{P}, s_{B}\right)$ in the following arguments to simplify and shorten our notation.

Our first theorem defines the separation of consumers into those that borrow and those that purchase and share.

Theorem 1. Consumers with a greater need purchase and share (i.e., are lenders), and consumers with a lesser need borrow (i.e., are borrowers).

Proof: By totally differentiating (8), we get

$$
\begin{aligned}
\frac{\partial \Lambda}{\partial \tilde{\theta}}= & \frac{\partial U\left(\tilde{\theta}, x_{L}\left(\tilde{\theta}, p_{S}, s_{L}\right)\right)}{\partial \tilde{\theta}}+\frac{\partial U\left(\tilde{\theta}, x_{L}\left(\tilde{\theta}, p_{S}, s_{L}\right)\right)}{\partial x_{L}} * \frac{\partial x_{L}\left(\tilde{\theta}, p_{S}, s_{L}\right)}{\partial \tilde{\theta}}-p_{S} * \frac{\partial x_{L}\left(\tilde{\theta}, p_{S}, s_{L}\right)}{\partial \tilde{\theta}} \\
& +s_{L} * \frac{\partial x_{L}\left(\tilde{\theta}, p_{S}, s_{L}\right)}{\partial \tilde{\theta}}-\frac{\partial U\left(\tilde{\theta}, x_{B}\left(\tilde{\theta}, p_{S}, s_{B}\right)\right)}{\partial \tilde{\theta}}-\frac{\partial U\left(\tilde{\theta}, x_{B}\left(\tilde{\theta}, p_{S}, s_{B}\right)\right)}{\partial x_{B}} * \frac{\partial x_{B}\left(\tilde{\theta}, p_{S}, s_{B}\right)}{\partial \tilde{\theta}} \\
& +p_{S} * \frac{\partial x_{B}\left(\tilde{\theta}, p_{S}, s_{B}\right)}{\partial \tilde{\theta}}+s_{B} * \frac{\partial x_{B}\left(\tilde{\theta}, p_{S}, s_{B}\right)}{\partial \tilde{\theta}} .
\end{aligned}
$$

Rearranging and cancelling terms and using the optimality conditions defined in (2) and (6), we have

$$
\frac{\partial \Lambda}{\partial \tilde{\theta}}=\frac{\partial U\left(\tilde{\theta}, x_{L}\left(\tilde{\theta}, p_{S}, s_{L}\right)\right)}{\partial \tilde{\theta}}-\frac{\partial U\left(\tilde{\theta}, x_{B}\left(\tilde{\theta}, p_{S}, s_{B}\right)\right)}{\partial \tilde{\theta}}
$$

From Assumption 2 it follows that both terms on the right hand side of (9) are positive. For $s_{L}=s_{B}=0$, the first term equals the second term and consequently (9) equals zero. We exclude this case from our analysis directly after Assumption 4 because the platform would not cover its 
fixed cost. Starting from $s_{L}=s_{B}=0$ and using Lemma 1 and Lemma 3, a marginal increase of $s_{B}$ results in a marginal decrease of $x_{B}\left(\tilde{\theta}, p_{S}, s_{B}\right)$ and a marginal increase of $s_{L}$ results in a marginal increase of $x_{L}\left(\tilde{\theta}, p_{S}, s_{L}\right)$. The resulting difference $x_{L}\left(\tilde{\theta}, p_{S}, s_{L}\right)-x_{B}\left(\tilde{\theta}, p_{S}, s_{B}\right)$ is positive. Treating this difference as small, $x_{L}\left(\tilde{\theta}, p_{S}, s_{L}\right)-x_{B}\left(\tilde{\theta}, p_{S}, s_{B}\right)$ represents a marginal increase in $x$. Thus, (9) represents the change in the marginal utility with an increasing need to use of the indifferent consumer which can be rewritten as $\partial \Lambda / \partial \tilde{\theta}=\partial^{2} U(\tilde{\theta}, x) / \partial x \partial \tilde{\theta}$. This term is positive from Assumption 3. Q.E.D.

In our running example, Theorem 1 implies that consumers with a lesser need to use a power drill borrow and consumers with a greater need purchase and share the power drill.

Lemma 5 determines the effects of the purchase price, the platform fees, the sharing price, and capacity on the indifferent consumer.

Lemma 5. The proportion of borrowers increases in the purchase price, decreases in the borrower fee, increases in the lender fee, decreases in the sharing price, and decreases in capacity.

Proof: Using Lemma 2 and totally differentiating (8) with respect to $p_{P}, s_{B}, s_{L}, p_{S}$, and $\bar{x}$, cancelling terms, using the optimality conditions of (2) and (6), and using the implicit function rule, we have

$$
\begin{gathered}
\frac{\partial \tilde{\theta}(\cdot)}{\partial p_{P}}=-\frac{\partial \Lambda / \partial p_{P}}{\partial \Lambda / \partial \tilde{\theta}}=-\frac{-1}{\partial \Lambda / \partial \tilde{\theta}}>0 \\
\frac{\partial \tilde{\theta}(\cdot)}{\partial s_{B}}=-\frac{\partial \Lambda / \partial s_{B}}{\partial \Lambda / \partial \tilde{\theta}}=-\frac{x_{B}\left(\tilde{\theta}, p_{S}, s_{B}\right)}{\partial \Lambda / \partial \tilde{\theta}}<0 \\
\frac{\partial \tilde{\theta}(\cdot)}{\partial s_{L}}=-\frac{\partial \Lambda / \partial s_{L}}{\partial \Lambda / \partial \tilde{\theta}}=-\frac{-\bar{x}+x_{L}\left(\tilde{\theta}, p_{S}, s_{L}\right)}{\partial \Lambda / \partial \tilde{\theta}}>0 \\
\frac{\partial \tilde{\theta}(\cdot)}{\partial p_{S}}=-\frac{\partial \Lambda / \partial p_{S}}{\partial \Lambda / \partial \tilde{\theta}}=-\frac{\bar{x}-x_{L}\left(\tilde{\theta}, p_{S}, s_{L}\right)+x_{B}\left(\tilde{\theta}, p_{S}, s_{B}\right)}{\partial \Lambda / \partial \tilde{\theta}}<0, \\
\frac{\partial \tilde{\theta}(\cdot)}{\partial \bar{x}}=-\frac{\partial \Lambda / \partial \bar{x}}{\partial \Lambda / \partial \tilde{\theta}}=-\frac{p_{S}-s_{L}}{\partial \Lambda / \partial \tilde{\theta}}<0 .
\end{gathered}
$$


From Theorem 1, the denominators of the five equations above are positive. Consequently, the first equation is positive and the second equation is negative. From the domain of $x \in[0, \bar{x}]$ it follows that the third equation is positive and the fourth equation is negative. From the domain of $s_{L} \in\left[0, p_{S}\right]$ it follows that the fifth equation is negative. Q.E.D.

Lemma 5 explains how external factors influence the number of lenders and borrowers of a durable good (cf., first, fourth, and fifth equation in the proof of Lemma 5), and how the sharing platform can influence the number of lenders and borrowers itself by adapting its platform fees (cf., second and third equation in the proof of Lemma 5).

\subsection{Platform Pricing Behavior}

As stated earlier, the monopoly sharing platform sets a borrower fee $s_{B}$ and a lender fee $s_{L}$, to be paid to the sharing platform for each transaction between borrowers and lenders. The aggregate shared usage time represents the minimum of aggregate demand of all borrowers and aggregate supply of all lenders.

Using Theorem 1, aggregate demand is represented by

$$
X\left(\theta, p_{S}, p_{P}, s_{B}, s_{L}, \bar{x}\right)=\int_{0}^{\tilde{\theta}(\cdot)} x_{B}\left(\theta, p_{S}, s_{B}\right) d \theta
$$

and aggregate supply is represented by

$$
Y\left(\theta, p_{S}, p_{P}, s_{B}, s_{L}, \bar{x}\right)=\int_{\tilde{\theta}(\cdot)}^{1} y\left(\theta, p_{S}, s_{L}, \bar{x}\right) d \theta
$$

The sharing platform also faces fixed costs, $C$, for setting up the platform. Consequently, the profit function of the sharing platform is

$$
\pi=\min \left\{X\left(\theta, p_{S}, p_{P}, s_{B}, s_{L}, \bar{x}\right), Y\left(\theta, p_{S}, p_{P}, s_{B}, s_{L}, \bar{x}\right)\right\}\left[s_{B}+s_{L}\right]-C .
$$

Based on this profit function we can state the profit maximization problem for two cases. 
Case 1: For the case where aggregate supply is greater or equal than aggregate demand, the profit maximization problem is given by

$$
\begin{gathered}
\max _{s_{B}, s_{L}} \pi=\max _{s_{B}, s_{L}}\left\{X\left(\theta, p_{S}, p_{P}, s_{B}, s_{L}, \bar{x}\right) *\left[s_{B}+s_{L}\right]-C\right\}, \\
\text { s.t. } \quad X\left(\theta, p_{S}, p_{P}, s_{B}, s_{L}, \bar{x}\right) \leq Y\left(\theta, p_{S}, p_{P}, s_{B}, s_{L}, \bar{x}\right) .
\end{gathered}
$$

In order to maximize the sharing platform's profit by choice of the platform fees $s_{B}$ and $s_{L}$, we again use the KKT theorem. The Lagrange function and its first order conditions are

$$
\begin{aligned}
L_{x}=\int_{0}^{\tilde{\theta}(\cdot)} x_{B}\left(\theta, p_{S}, s_{B}\right) d \theta *\left[s_{B}+s_{L}\right]-\lambda_{1}\left(\int_{0}^{\tilde{\theta}(\cdot)} x_{B}\left(\theta, p_{S}, s_{B}\right) d \theta-\int_{\tilde{\theta}(\cdot)}^{1} y\left(\theta, p_{S}, s_{L}, \bar{x}\right) d \theta\right)-C \\
\frac{\partial L_{x}}{\partial s_{B}}=\int_{0}^{\tilde{\theta}(\cdot)} x_{B}\left(\theta, p_{S}, s_{B}\right) d \theta+\left[s_{B}+s_{L}\right] *\left[\int_{0}^{\tilde{\theta}(\cdot)} \frac{\partial x_{B}\left(\theta, p_{S}, s_{B}\right)}{\partial s_{B}} d \theta+x_{B}\left(\tilde{\theta}, p_{S}, s_{B}\right) * \frac{\partial \tilde{\theta}(\cdot)}{\partial s_{B}}\right] \\
-\lambda_{1}\left[\int_{0}^{\tilde{\theta}(\cdot)} \frac{\partial x_{B}\left(\theta, p_{S}, s_{B}\right)}{\partial s_{B}} d \theta+y\left(\tilde{\theta}, p_{S}, s_{L}, \bar{x}\right) * \frac{\partial \tilde{\theta}(\cdot)}{\partial s_{B}}+x_{B}\left(\tilde{\theta}, p_{S}, s_{B}\right) * \frac{\partial \tilde{\theta}(\cdot)}{\partial s_{B}}\right], \\
\frac{\partial L_{x}}{\partial s_{L}}=\int_{0}^{\tilde{\theta}(\cdot)} x_{B}\left(\theta, p_{S}, s_{B}\right) d \theta+\left[s_{B}+s_{L}\right] * x_{B}\left(\tilde{\theta}, p_{S}, s_{B}\right) * \frac{\partial \tilde{\theta}(\cdot)}{\partial s_{L}} \\
\quad-\lambda_{1}\left[-\int_{\tilde{\theta}(\cdot)}^{1} \frac{\partial y\left(\theta, p_{S}, s_{L}, \bar{x}\right)}{\partial s_{L}} d \theta+y\left(\tilde{\theta}, p_{S}, s_{L}, \bar{x}\right) * \frac{\partial \tilde{\theta}(\cdot)}{\partial s_{L}}+x_{B}\left(\tilde{\theta}, p_{S}, s_{B}\right) * \frac{\partial \tilde{\theta}(\cdot)}{\partial s_{L}}\right],(12)
\end{aligned}
$$

and we have the KKT conditions

$$
\begin{gathered}
\text { (i) } \frac{\partial L_{x}}{\partial s_{B}}=0, \quad\left(\text { ii) } \quad \frac{\partial L_{x}}{\partial s_{L}}=0\right. \\
\text { (iii) } X\left(\theta, p_{S}, p_{P}, s_{B}, s_{L}, \bar{x}\right) \leq Y\left(\theta, p_{S}, p_{P}, s_{B}, s_{L}, \bar{x}\right) ; \lambda_{1} \geq 0 \\
\lambda_{1}\left[X\left(\theta, p_{S}, p_{P}, s_{B}, s_{L}, \bar{x}\right)-Y\left(\theta, p_{S}, p_{P}, s_{B}, s_{L}, \bar{x}\right)\right]=0 .
\end{gathered}
$$

Lemma 6. In Case 1, a monopoly sharing platform only maximizes profits by setting the platform fees in a way that aggregate demand equals aggregate supply.

Proof: To find a solution we consider if the constraint in (10) is binding. Suppose $X\left(\theta, p_{S}, p_{P}, s_{B}, s_{L}, \bar{x}\right)<$ $Y\left(\theta, p_{S}, p_{P}, s_{B}, s_{L}, \bar{x}\right):$ From KKT condition (iii) follows $\lambda_{1}=0$ and consequently the second line 
of (12) is zero. From Lemma 5 follows that the first line of (12) is positive. Consequently, we have $\partial L_{x} / \partial s_{L}>0$ and KKT condition (ii) is violated.

Now suppose $X\left(\theta, p_{S}, p_{P}, s_{B}, s_{L}, \bar{x}\right)=Y\left(\theta, p_{S}, p_{P}, s_{B}, s_{L}, \bar{x}\right)$ : From KKT condition (iii) it follows $\lambda_{1}>0$. Consequently, KKT condition (i) and (ii) can be fulfilled and this case represents a valid solution. Q.E.D.

Case 2: For the case where aggregate supply is lower or equal than aggregate demand, the profit maximization problem is given by

$$
\begin{gathered}
\max _{s_{B}, s_{L}} \pi=\max _{s_{B}, s_{L}}\left\{Y\left(\theta, p_{S}, p_{P}, s_{B}, s_{L}, \bar{x}\right) *\left[s_{B}+s_{L}\right]-C\right\}, \\
\text { s.t. } \quad Y\left(\theta, p_{S}, p_{P}, s_{B}, s_{L}, \bar{x}\right) \leq X\left(\theta, p_{S}, p_{P}, s_{B}, s_{L}, \bar{x}\right) .
\end{gathered}
$$

As in Case 1, we use the KKT theorem. The Lagrange function and its first order conditions are

$$
\begin{gathered}
L_{y}=\int_{\tilde{\theta}(\cdot)}^{1} y\left(\theta, p_{S}, s_{L}, \bar{x}\right) d \theta *\left[s_{B}+s_{L}\right]-\lambda_{1}\left[\int_{\tilde{\theta}(\cdot)}^{1} y\left(\theta, p_{S}, s_{L}, \bar{x}\right) d \theta-\int_{0}^{\tilde{\theta}(\cdot)} x_{B}\left(\theta, p_{S}, s_{B}\right) d \theta\right]-C, \\
\frac{\partial L_{y}}{\partial s_{B}}=\int_{\tilde{\theta}(\cdot)}^{1} y\left(\theta, p_{S}, s_{L}, \bar{x}\right) d \theta ?\left[s_{B}+s_{L}\right] * y\left(\tilde{\theta}, p_{S}, s_{L}, \bar{x}\right) * \frac{\partial \tilde{\theta}(\cdot)}{\partial s_{B}} \\
\quad-\lambda_{1}\left[-\int_{0}^{\left({ }^{2}(\cdot)\right.} \frac{\partial x_{B}\left(\theta, p_{S}, s_{B}\right)}{\partial s_{B}} d \theta-y\left(\tilde{\theta}, p_{S}, s_{L}, \bar{x}\right) * \frac{\partial \tilde{\theta}(\cdot)}{\partial s_{B}}-x_{B}\left(\tilde{\theta}, p_{S}, s_{B}\right) * \frac{\partial \tilde{\theta}(\cdot)}{\partial s_{B}}\right],(14) \\
\frac{\partial L_{y}}{\partial s_{L}=} \quad \int_{\tilde{\theta}(\cdot)}^{1} y\left(\theta, p_{S}, s_{L}, \bar{x}\right) d \theta+\left[s_{B}+s_{L}\right] *\left[\int_{\tilde{\theta}(\cdot)}^{1} \frac{\partial y\left(\tilde{\theta}, p_{S}, s_{L}, \bar{x}\right)}{\partial s_{L}} d \theta-y\left(\tilde{\theta}, p_{S}, s_{L}, \bar{x}\right) * \frac{\partial \tilde{\theta}(\cdot)}{\partial s_{L}}\right] \\
\quad-\lambda_{1}\left[\int_{\tilde{\theta}(\cdot)}^{1} \frac{\partial y\left(\tilde{\theta}, p_{S}, s_{L}, \bar{x}\right)}{\partial s_{L}} d \theta-y\left(\tilde{\theta}, p_{S}, s_{L}, \bar{x}\right) * \frac{\partial \tilde{\theta}(\cdot)}{\partial s_{L}}-x_{B}\left(\tilde{\theta}, p_{S}, s_{B}\right) * \frac{\partial \tilde{\theta}(\cdot)}{\partial s_{L}}\right],
\end{gathered}
$$

and we have the KKT conditions

$$
\begin{gathered}
\text { (i) } \frac{\partial L_{y}}{\partial s_{B}}=0, \quad\left(\text { ii) } \frac{\partial L_{y}}{\partial s_{L}}=0\right. \\
\text { (iii) } Y\left(\theta, p_{S}, p_{P}, s_{B}, s_{L}, \bar{x}\right) \leq X\left(\theta, p_{S}, p_{P}, s_{B}, s_{L}, \bar{x}\right) ; \lambda_{1} \geq 0 \\
\lambda_{1}\left[Y\left(\theta, p_{S}, p_{P}, s_{B}, s_{L}, \bar{x}\right)-X\left(\theta, p_{S}, p_{P}, s_{B}, s_{L}, \bar{x}\right)\right]=0 .
\end{gathered}
$$


Lemma 7. In Case 2, a monopoly sharing platform only maximizes profits by setting the platform fees in a way that aggregate demand equals aggregate supply.

Proof: To find a solution we consider if the constraint in (13) is binding. Suppose $Y\left(\theta, p_{S}, p_{P}, s_{B}, s_{L}, \bar{x}\right)<$ $X\left(\theta, p_{S}, p_{P}, s_{B}, s_{L}, \bar{x}\right)$ : From KKT condition (iii) follows $\lambda_{1}=0$ and consequently the second line of (14) is zero. From Lemma 5 follows that the first line of (14) is positive. Consequently, we have $\partial L_{y} / \partial s_{B}>0$ and KKT condition (i) is violated.

Now suppose $Y\left(\theta, p_{S}, p_{P}, s_{B}, s_{L}, \bar{x}\right)=X\left(\theta, p_{S}, p_{P}, s_{B}, s_{L}, \bar{x}\right)$ : From KKT condition (iii) it follows $\lambda_{1}>0$. Consequently, KKT condition (i) and (ii) can be fulfilled and this case represents a valid solution. Q.E.D.

Combining Lemma 6 and Lemma 7, we find that a sharing platform has to set the platform fees in a way that the market clears, in other words, to maximize profits platform fees have to be set so that aggregate demand equals aggregate supply. We identify the platform fees that result in such a market by the market-clearing condition

$$
\int_{\tilde{\theta}(\cdot)}^{1} y\left(\theta, p_{S}, s_{L}, \bar{x}\right) d \theta-\int_{0}^{\tilde{\theta}(\cdot)} x_{B}\left(\theta, p_{S}, s_{B}\right) d \theta=0=\epsilon\left(p_{S}, s_{B}, s_{L}, p_{P}, \bar{x}\right)
$$

where $\epsilon\left(p_{S}, s_{B}, s_{L}, p_{P}, \bar{x}\right)$ implicitly defines the lender fee $s_{L}\left(p_{S}, s_{B}, p_{P}, \bar{x}\right)$ and the borrower fee $s_{B}\left(p_{S}, s_{L}, p_{P}, \bar{x}\right)$. Based on this market-clearing condition, Lemma 8 explains how aggregate demand and supply simultaneously change as a result of changes in the external factors, and the platform fees.

Lemma 8. Aggregate demand increases and aggregate supply decreases in the lender fee and purchase price. Aggregate supply increases and aggregate demand decreases in the borrower fee, the sharing price, and capacity. 
Proof: Totally differentiating (16) with respect to $p_{S}, s_{B}, s_{L}, p_{P}$, and $\bar{x}$, we have

$$
\begin{aligned}
\frac{\partial \epsilon\left(p_{S}, s_{B}, s_{L}, p_{P}, \bar{x}\right)}{\partial p_{S}}= & -\int_{0}^{\tilde{\theta}(\cdot)} \frac{\partial x_{B}\left(\theta, p_{S}, s_{B}\right)}{\partial p_{S}} d \theta+\int_{\tilde{\theta}(\cdot)}^{1} \frac{\partial y\left(\theta, p_{S}, s_{L}, \bar{x}\right)}{\partial p_{S}} d \theta \\
& -y\left(\tilde{\theta}, p_{S}, s_{L}, \bar{x}\right) * \frac{\partial \tilde{\theta}(\cdot)}{\partial p_{S}}-x_{B}\left(\tilde{\theta}, p_{S}, s_{B}\right) * \frac{\partial \tilde{\theta}(\cdot)}{\partial p_{S}}>0, \\
\frac{\partial \epsilon\left(p_{S}, s_{B}, s_{L}, p_{P}, \bar{x}\right)}{\partial s_{B}}= & -\int_{0}^{\tilde{\theta}(\cdot)} \frac{\partial x_{B}\left(\theta, p_{S}, s_{B}\right)}{\partial s_{B}} d \theta-y\left(\tilde{\theta}, p_{S}, s_{L}, \bar{x}\right) * \frac{\partial \tilde{\theta}(\cdot)}{\partial s_{B}} \\
& -x_{B}\left(\tilde{\theta}, p_{S}, s_{B}\right) * \frac{\partial \tilde{\theta}(\cdot)}{\partial s_{B}}>0, \\
\frac{\partial \epsilon\left(p_{S}, s_{B}, s_{L}, p_{P}, \bar{x}\right)}{\partial s_{L}}= & \int_{\tilde{\theta}(\cdot)}^{1} \frac{\partial y\left(\theta, p_{S}, s_{L}, \bar{x}\right)}{\partial s_{L}} d \theta-y\left(\tilde{\theta}, p_{S}, s_{L}, \bar{x}\right) * \frac{\partial \tilde{\theta}(\cdot)}{\partial s_{L}} \\
& -x_{B}\left(\tilde{\theta}, p_{S}, s_{B}\right) * \frac{\partial \tilde{\theta}(\cdot)}{\partial s_{L}}<0, \\
\frac{\partial \epsilon\left(p_{S}, s_{B}, s_{L}, p_{P}, \bar{x}\right)}{\partial p_{P}}= & -y\left(\tilde{\theta}, p_{S}, s_{L}, \bar{x}\right) * \frac{\partial \tilde{\theta}(\cdot)}{\partial p_{P}}-x_{B}\left(\tilde{\theta}, p_{S}, s_{B}\right) * \frac{\partial \tilde{\theta}(\cdot)}{\partial p_{P}}<0, \\
\frac{\partial \epsilon\left(p_{S}, s_{B}, s_{L}, p_{P}, \bar{x}\right)}{\partial \bar{x}}= & \int_{\tilde{\theta}(\cdot)}^{1} \frac{\partial y\left(\theta, p_{S}, s_{L}, \bar{x}\right)}{\partial \bar{x}} d \theta-y\left(\tilde{\theta}, p_{S}, s_{L}, \bar{x}\right) * \frac{\partial \tilde{\theta}(\cdot)}{\partial \bar{x}} \\
& -x_{B}\left(\tilde{\theta}, p_{S}, s_{B}\right) * \frac{\partial \tilde{\theta}(\cdot)}{\partial \bar{x}}>0 .
\end{aligned}
$$

From the borrowers' individual elasticities of demand explained in Lemma 1, the lenders' individual elasticities of supply explained in Lemma 4, and the changes in the number of lenders and borrowers explained in Lemma 5 we get the signs of the five equations above. Q.E.D.

The first equation represents the effect of the sharing price on aggregate demand and supply. A marginal increase of the sharing price decreases the demand of borrowers and increases the supply of lenders. These effects are represented by the first two terms. Moreover, the supply increases and the demand decreases from a shift of the indifferent consumer. This effect is represented by the last two terms. Overall, a marginal increase of the sharing price leads to a greater aggregate supply than demand.

The second equation represents the effect of the borrower fee on aggregated demand and supply. A marginal increase of the borrower fee decreases the demand of all borrowers represented by the 
first term and has no effect on the supply of lenders. Moreover, the supply increases and the demand decreases from a shift of the indifferent consumer. This effect is represented by the last two terms. Overall, a marginal increase of the borrower fee leads to a greater aggregate supply than demand.

The third equation represents the effect of the lender fee on aggregated demand and supply. A marginal increase of the lender fee decreases the supply of lenders represented by the first term and has no effect on the demand of borrowers. Moreover, the supply decreases and the demand increases from a shift of the indifferent consumer. This effect is represented by the last two terms. Overall, a marginal increase of the lender fee leads to a greater aggregate demand than supply.

The fourth equation represents the effect of the purchase price on aggregated demand and supply. The only effect from a marginal increase of the purchase price is a shift of the indifferent consumer resulting in an increasing aggregate demand and a decreasing aggregate supply.

The last equation represents the effect of capacity on aggregated demand and supply. A marginal increase in capacity increases the supply of all lenders represented by the first term and has no effect on the demand of all borrowers. Moreover, the supply increases and the demand decreases from a shift of the indifferent consumer. This effect is represented by the last two terms. Overall, a marginal increase in capacity leads to a greater aggregate supply than demand.

Consequently, isolated changes in the external factors and the platform fees result in a violation of the market-clearing condition described in (16). To maintain the market-clearing condition the sharing platform has to adapt its platform fees in response to the effects explained in Lemma 8. Theorem 2 defines the comparative statics of the platform fees as a result of changes in the external factors and of changes in the complement platform fee:

Theorem 2. The lender fee is increasing in the sharing price, is increasing in the borrower fee, is 
increasing in capacity, and is decreasing in the purchase price. The borrower fee is increasing in the purchase price, is increasing in the lender fee, is decreasing in the sharing price, and is decreasing in capacity.

Proof: From Lemma 8 and the implicit function rule, we get the effects on $s_{L}$ by

$$
\begin{aligned}
& \frac{\partial s_{L}}{\partial p_{S}}=-\frac{\partial \epsilon\left(p_{S}, s_{B}, s_{L}, p_{P}, \bar{x}\right) / \partial p_{S}}{\partial \epsilon\left(p_{S}, s_{B}, s_{L}, p_{P}, \bar{x}\right) / \partial s_{L}}>0, \quad \frac{\partial s_{L}}{\partial s_{B}}=-\frac{\partial \epsilon\left(p_{S}, s_{B}, s_{L}, p_{P}, \bar{x}\right) / \partial s_{B}}{\partial \epsilon\left(p_{S}, s_{B}, s_{L}, p_{P}, \bar{x}\right) / \partial s_{L}}>0 \\
& \frac{\partial s_{L}}{\partial p_{P}}=-\frac{\partial \epsilon\left(p_{S}, s_{B}, s_{L}, p_{P}, \bar{x}\right) / \partial p_{P}}{\partial \epsilon\left(p_{S}, s_{B}, s_{L}, p_{P}, \bar{x}\right) / \partial s_{L}}<0, \quad \frac{\partial s_{L}}{\partial \bar{x}}=-\frac{\partial \epsilon\left(p_{S}, s_{B}, s_{L}, p_{P}, \bar{x}\right) / \partial \bar{x}}{\partial \epsilon\left(p_{S}, s_{B}, s_{L}, p_{P}, \bar{x}\right) / \partial s_{L}}>0
\end{aligned}
$$

and the effects on $s_{B}$ by

$$
\begin{aligned}
& \frac{\partial s_{B}}{\partial p_{S}}=-\frac{\partial \epsilon\left(p_{S}, s_{B}, s_{L}, p_{P}, \bar{x}\right) / \partial p_{S}}{\partial \epsilon\left(p_{S}, s_{B}, s_{L}, p_{P}, \bar{x}\right) / \partial s_{B}}<0, \quad \frac{\partial s_{B}}{\partial s_{L}}=-\frac{\partial \epsilon\left(p_{S}, s_{B}, s_{L}, p_{P}, \bar{x}\right) / \partial s_{L}}{\partial \epsilon\left(p_{S}, s_{B}, s_{L}, p_{P}, \bar{x}\right) / \partial s_{B}}>0, \\
& \frac{\partial s_{B}}{\partial p_{P}}=-\frac{\partial \epsilon\left(p_{S}, s_{B}, s_{L}, p_{P}, \bar{x}\right) / \partial p_{P}}{\partial \epsilon\left(p_{S}, s_{B}, s_{L}, p_{P}, \bar{x}\right) / \partial s_{B}}>0, \quad \frac{\partial s_{B}}{\partial \bar{x}}=-\frac{\partial \epsilon\left(p_{S}, s_{B}, s_{L}, p_{P}, \bar{x}\right) / \partial \bar{x}}{\partial \epsilon\left(p_{S}, s_{B}, s_{L}, p_{P}, \bar{x}\right) / \partial s_{B}}<0 .
\end{aligned}
$$

Q.E.D.

The comparative statics of the lender and borrower fees to each other are positive, indicating that these fees are strategic complements. This is because a reduction in one requires a reduction in the other in order to maintain the market-clearing condition, and vice versa. For given external factors, the comparative statics of the lender and borrower fees can be used to change their absolute level. This is required if platform profits can be increased through changing the absolute level of the platform fees. The profit maximizing level of the platform fees depend on the relative magnitudes of the platform fee elasticities of demand explained in Lemma 1, the platform fee elasticities of supply explained in Lemma 4, and the effects of changing platform fees on the number of lenders and borrowers explained in Lemma 5 .

Moreover, the comparative statics show that in order to remain profit maximizing and maintain the market-clearing condition, a monopoly sharing platform has to adapt their platform fees in 
response to changes in purchase price, sharing price, and capacity of a durable good as follows: the lender fee has to be increased or the borrower fee has to be decreased with an increasing sharing price, an increase in capacity, and a decreasing purchase price of a durable good and vice versa. Whether to adapt the lender fee or the borrower fee depends on the relative magnitude of the external factor elasticities of demand explained in Lemma 1, the external factor elasticities of supply explained in Lemma 4, and the effects of changing external factors on the number of lenders and borrowers explained in Lemma 5.

\section{Conclusion and Discussion}

Rifkin (2000) predicted in the year 2000 that "ownership is steadily being replaced by access". A couple of years later several sharing platforms such as Zilok.com emerged. These sharing platforms aim to maximize profits and need to know how to optimally price lenders and borrowers in response to changes in external factors such as the sharing price, purchase price, and capacity of a good.

We find that sharing platforms maximize profits only if the supplied usage time of a durable good provided by lenders through a sharing platform matches the demanded usage time requested by borrowers - that is, the market must clear for platform fees to be profit maximizing. We further find that the market-clearing condition requires that lender and borrower fees are classic strategic complements and we show how sharing platforms have to adapt their platform fees in response to a changing sharing price, purchase price, and durability.

Most pricing models of existing sharing platforms have not implemented pricing models where platform fees dynamically change for the same durable good in response to external factors. Although in a different setting, an exception is Uber.com that dynamically adapts the sharing price in response to changing demand and supply in the sharing of transportation services. The major 
difference between Uber.com and sharing platforms for durable goods we study, aside from features of the setting where in Uber.com participation in market sides is pre-determined, capacity is flexible, etc., is that Uber.com not only decides on the platform fees but also on the sharing price.

Sharing platforms for durable goods can only decide on the platform fees (i.e., the sharing price is set by the lender). The vast majority of sharing platforms such as Zilok.com only charge a percent-of-value lender fee representing a percentage rate of the total sharing price and do not charge borrowers. Our model results indicate that such a percent-of-value lender fee may be a valid pricing model for lenders as long as the sharing platform is able to clear the market by using this mechanism. However, if demand for sharing a durable good is higher than supply, then even with a very low lender fee, raising a borrower fee can become necessary to fulfill the market-clearing condition and to maximize profits. In our model, we found that such a borrower fee has to be reduced with an increasing sharing price to maintain the market-clearing condition. Subsequently, a percent-of-value borrower fee (e.g. charged by Airbnb.com) cannot continuously maximize profits. These findings indicate that commonly applied one-sided pricing models of sharing platforms can be improved.

Because not all of the factors that influence platform fees can be continuously observed, sharing platforms may implement the relations defined in the Lemmas and Theorems as rule-based pricing mechanisms (cf., Bădică, Bădită, \& Ganzha, 2006). In this way, sharing platforms can ensure that the platform fees are adapted in an automated way in response to changes of, for example, the sharing price or the purchase price of a durable good, and may dynamically maximize their profits.

Although there are benefits from analyzing platform pricing in a general analytical model specifically the wide range to which the results apply - there are still some limitations that represent starting points for future research. 
Non-negative platform fees: In our model we assume non-negative platform fees $\left(s_{L} \in\left[0, p_{S}\right]\right.$; $s_{B} \in\left[0, p_{P}\right] ; s_{L}+s_{B} \in R^{+}$). We made this assumption as sustainable business models of sharing platforms require positive fees to cover fixed costs and we do not observe negative fees charged by operating sharing platforms in practice. However, especially for new start-ups, it may be the case that supply for sharing a durable good is zero or very low while demand is very high. In this case, to encourage supply on the sharing platform, it may be profit maximizing (at least in the short run) to subsidize lenders by a negative fee. To analyze if and how our findings change in the case of negative platform fees likely requires a diffusion model and is a task for future research.

Non-linear platform fees: We implicitly assume the transaction-based platform fees linearly increase in the shared usage time of a durable good. However, there are pricing models where the marginal platform fees decrease in the shared usage time (e.g., Zilok.com charges a lender fee which is decreasing from $9 \%$ to $5 \%$ in the shared usage time of a durable good). To analyze the effects of different non-linear pricing models, our model would have to be extended by reduced-form functions for the platform fees.

Fixed platform fees: If the platform fees take the form of a membership (or fixed) fee that can differ between the membership fee charged to borrowers and lenders, then the difference in these fees would be an argument to the function that defines the consumer that is indifferent between borrowing and lending. Consequently, the difference in membership fees could be used by the sharing platform to control the number of borrowers and lenders. The membership fees can also be used to make additional profit from consumers if the consumer need for the durable good is sufficiently large.

Externalities: Sharing of durable goods can have positive externalities (e.g., lowering environmental damage, fostering communities), and negative externalities (e.g., downturn in demand for 
buying durable goods and decreasing revenues for traditional firms). A possible extension of our model is to incorporate such externalities and analyzing their impact on our findings.

Welfare and policy: A further direction for future research is to extend our model to include welfare analysis. This is of special interest, as existing literature has not yet reached a consensus on the impact of the sharing economy on producer surplus. For instance, Zervas et al. (2014) empirically found that Airbnb.com successfully competes with established firms in the hospitality industry, leading to decreasing hotel revenues. In contrast, Jiang and Tian (2015) highlight that consumers have higher reservation prices for durable goods because they anticipate additional revenues from sharing. Consequently, manufacturers of durable goods may benefit from sharing as they can charge higher purchase prices. Moreover, the impact of the sharing economy on the overall welfare including consumer surplus, producer surplus, and different externalities is unclear. There is also a lack of policy frameworks for regulating the new sharing economy (Dervojeda et al., 2013). Against this backdrop, another interesting direction of further research is analyzing different policy measures for the $\mathrm{C} 2 \mathrm{C}$ sharing market and their impact on social welfare.

B2C business models: Beside the $\mathrm{C} 2 \mathrm{C}$ sharing business model analyzed in this research, $\mathrm{B} 2 \mathrm{C}$ sharing is another business model that is commonly applied in the sharing economy. In our current C2C model, consumers decide to purchase and share (i.e., being a lender) or borrow (i.e., being a borrower) a homogeneous durable good based on the utilities they expect from the two options. In contrast, in a B2C model, lenders and borrowers are mutually exclusive groups as lenders are firms that maximizes profits while borrowers are consumers that maximize utility. As this represents a substantial different model setup, we aim to analyze in future research whether our findings also hold in a B2C sharing model. 


\section{References}

Alba, J., Weitz, B., Janiszewski, C., Lutz, R., Sawyer, A., Wood, S., \& Lynch, J. (1997). Interactive home shopping: Consumer, retailer, and manufacturer incentives to participate in electronic marketplaces. Journal of Marketing, 61(3), 38-53.

Armstrong, M. (2006). Competition in two-sided markets. The RAND Journal of Economics, 37(3), 668-691.

Becker, G. S. (1976). The economic Approach to Human Behavior. The University Press of Chicago, Chicago, Il, USA.

Belk, R. (2007). Why Not Share Rather Than Own?. The ANNALS of the American Academy of Political and Social Science, 611, 126-140.

Belk, R. (2010). Sharing. Journal of Consumer Research, 36(5), 715-734.

Botsman, R., \& Rogers, R. (2010). What's Mine Is Yours: The Rise of Collaborative Consumption. HarperCollins, New York, NY, USA.

Boyd, S., \& Vandenberghe, L. (2004). Convex Optimization. Cambridge University Press, New York, NY, USA.

Brock, W. A., \& Evans, D. S. (1985). The economics of regulatory tiering. The RAND Journal of Economics, 16(3), 398-409.

Bădică, C., Bădită, A., \& Ganzha, M. (2006). Implementing rule-based mechanisms for agent-based price negotiations. Proceedings of the 2006 ACM Symposium on Applied Computing, New York, NY, USA. 
Caillaud, B., \& Jullien, B. (2003). Chicken \& egg: Competition among intermediation service providers. The RAND Journal of Economics, 34(2), 309-328.

Chen, Y. (2009). Possession and access: Consumer desires and value perceptions regarding contemporary art collection and exhibit visits. Journal of Consumer Research, 35(6), 925-940.

Cusumano, M. A. (2014). How traditional firms must compete in the sharing economy. Communications of the ACM, 58(1), 32-34.

Dervojeda, K., Verzijil, D., Hagtagaal, F., Lengton, M. , Rouwmaat, E., Monfardini, E., \& Frideres L. (2013). The sharing economy: Accessibility based business models for peer-to-peer markets. European Commission: Business Innovation Observatory. Retrieved February, 2015, from http:// ec.europa.eu/DocsRoom/documents/13413/attachments/2/translations/en/renditions/native.

Einav, L., Farronato, C., \& Levin, J. (2016). Peer-to-Peer Markets. Annual Review of Economics, $8,615-635$.

Eisenmann, T., Parker G., \& Van Alstyne, M. W. (2006). Strategies for two-sided markets. Harvard Business Review, 84(10), 92-101.

Fraiberger, S., \& Sundararajan A. (2015). Peer-to-Peer Rental Markets in the Sharing Economy. Social Science Research Network. Retrieved November, 2016, from https://papers.ssrn.com/sol3/papers.cfm?abstract_id=2574337.

Jiang, B., \& Tian, L. (2015). Collaborative consumption: Strategic and economic implications of product sharing. Working Paper Washington University of St. Louis.

Knote, R., \& Blohm, I. (2016). Deconstructing the Sharing Economy: On the Relevance for IS Research. Proceedings of the Multikonferenz Wirtschaftsinformatik, 2016, Illmenau, Germany. 
Lamberton, C. P., \& Rose, R. L. (2012). When is ours better than mine? A framework for understanding and altering participation in commercial sharing systems. Journal of Marketing, 76(4), $109-125$.

Lee, R. S., \& Wu, T. (2009). Subsidizing creativity through network design: Zero-pricing and net neutrality. The Journal of Economic Perspectives, 23(3), 61-76.

Levi, M. D., \& Nault, B. R. (2004). Converting technology to mitigate environmental damage. Management Science, 50(8), 1015-1030.

Malhotra, A., \& Van Alstyne, M., (2014). The dark side of the sharing economy and how to lighten it. Communications of the ACM, 57(11), 24-27.

Matzner, M., Chasin F., \& Todenhoefer L., (2015). To Share or Not to Share: Towards Understanding the Antecedents of Participation in IT Enabled Sharing Services. Proceedings of the European Conference on Information Systems, 2015, Muenster, Germany.

Moehlmann, M. (2015). Collaborative consumption: determinants of satisfaction and the likelyhood of using a sharig option again. Journal of Consumer Behavior, 14(3), 193-207.

Mueller, M. P. (2014). An economic analysis of online sharing systems' implications on social welfare. Proceedings of the European Conference on Information Systems, 2014, Tel Aviv, Israel.

Nault, B. R. (1996). Equivalence of taxes and subsidies in the control of production externalities. Management Science, 42(3), 307-320.

Phipps, M., Ozanne, L. K., Luchs, M. G., Subrahmanyan, S., Kapitan, S., Catlin, J. R., Gau, R., Naylor, R. W., Rose, R. L., \& Simpson, B. (2013). Understanding the inherent complexity of sustainable consumption: A social cognitive framework. Journal of Business Research, 66(8), $1227-1234$. 
PwC (2015). The sharing economy - Sizing the revenue opportunity. Retrieved November, 2015, from http://www.pwc.co.uk/issues/megatrends/collisions/sharingeconomy/the-sharingeconomy-sizing-the-revenue-opportunity.html.

Rifkin, J. (2000). The Age of Access: The New Culture of Hypercapitalism where all of Life is a paid-for Experience. Putnam, New York, NY, USA.

Rochet, J. C., \& Tirole, J. (2006). Two-sided markets: a progress report. The RAND Journal of Economics, 37(3), 645-667.

Rysman, M. (2009). The economics of two-sided markets. The Journal of Economic Perspectives, $23(3), 125-143$.

Sundararajan, A. (2016). The Sharing Economy. MIT Press, Cambridge, MA, USA.

Weber, T. A. (2014). Intermediation in a sharing economy: Insurance, moral hazard, and rent extraction. Journal of Management Information Systems, 31(3), 35-71.

Zervas, G., Proserpio, D., \& Byers, J. (2014). The rise of the sharing economy: Estimating the impact of airbnb on the hotel industry. Working Paper Boston University. 